International Journal of Agriculture, Environment and Bioresearch

Vol. 4, No. 04; 2019

ISSN: $2456-8643$

\title{
SOIL FERTILITY STATUS AND CROP YIELD AS INFLUENCED BY ALBIZIA LEBBECK BENTH (RATLE TREE) IN ALLEY CROPPING SYSTEM
}

\author{
KAREEM, I. A. ${ }^{1}$ and OJO, M. O. ${ }^{2}$ \\ ${ }^{1}$ Department of Plant Science \& Biotechnology, Faculty of Science, Adekunle Ajasin University,Akungba Akoko, \\ Ondo State, Nigeria \\ ${ }^{2}$ Department of Forestry and Wildlife Management, Faculty of Agriculture, Adekunle Ajasin University, \\ Akungba Akoko, Ondo State, Nigeria. \\ http://doi.org/10.35410/IJAEB.2019.4404
}

\begin{abstract}
Soil nutrient augmentation by some nitrogen (N2) fixing trees/shrubs coupled with their profuse litter cannot be over emphasized since most of them are deciduous. Thus, the influence of Albizia lebbeck Benth (its green manure and N2 fixation activities of its 6 months' old tree rows when first planted) on soil fertility under alley cropping (an agro-forestry system) with Irish potato (Solanum tuberosum L.) was investigated. The experimental design was a randomized complete block design (RCBD) comprising five treatments (T0 - T4) and three replicates. Soil sample analyses (pre and post experiment) were done. Tending operations and data collection on the morphological and yield parameters of the test crop throughout the five cropping seasons were carried out. Results on the soil physical properties indicated that the nine (9) samples from the three soil depths of T4 were predominantly sandy loam (except two samples) sequel to the fact that $\mathrm{T} 4$ received the highest rate of green manure application (10 ton ha-1) and also had A. lebbeck tree rows. Thus, a little (non-significant) difference between the pre and post planting soil texture was observed and the textural classes were mainly loamy textured with sandy clay loam, clay loam and sandy loam constituting the dominant textural classes. Regarding the soil chemical properties, the organic matter and \% N2 were very low and the values decreased from pre planting to after planting (no significant difference between treatments /blocks) due to crop removal. A. lebbeck green manure and its tree rows significantly $(\mathrm{P}<0.5)$ influenced the available $\mathrm{P}$ and $\mathrm{K}$ at three soil depths and block effects were observed at significant level (P < 0.5) on the $\mathrm{pH}$ and $\mathrm{Mg}$. The morphological parameters (plant height, leaf count and collar girth) except stem count were highly influenced by the different levels of Albizia lebbeck green manure application and its tree rows (sequel to $\mathrm{N} 2$ fixation) at $\mathrm{P}<0.1$ which subsequently brought about significant differences in yield (tuber count $(\mathrm{P}<0.5)$ and tuber weight $(\mathrm{P}<$ 0.01).of the crop (Irish potato) in all the 5 treatments and throughout the 5 cropping seasons owing to modification / improvement on the soil nutrient status in the agro-forestry farm.
\end{abstract}

Keywords: Soil fertility, Albizia lebbeck, influence, crop yield, alley cropping. 
Vol. 4, No. 04; 2019

ISSN: $2456-8643$

\section{INTRODUCTION}

The impoverished nature of soils in most farm lands especially of developing countries is indubitable. The organic matter content on the soil surface is being destroyed by wildfire/bush burning in the forest and savanna ecosystems annually (Okonkwo and Kareem, 1999) coupled with the consumption of much of the organic matter by termites most especially in the semiarid areas (Gachene and Kimaru, 2003). Even, the nitrogen that is abundantly available in the atmosphere (about 79\%) is very deficient in most soils. Several tons of chemical (nitrogenous) fertilizers are procured yearly to remedy soil nitrogen deficiencies and besides its exorbitance, its application could adversely affect the ozone layer thereby causing increase in skin cancer and rates of mutation in organisms due to harmful radiation (Alexander, 1982). Integration of nonnitrogen and nitrogen fixing trees into agro-forestry systems has been identified as one of the ways of increasing the organic matter and nitrogen content in most savanna soils. Alasiri (1997) asserted that most savanna soils are low in nutrients and poor structure due to continuous cultivation. In soil fertility improvement and land reclamation, nitrogen fixing trees can play significant roles particularly under alley cropping system which has been known to enhance both nutrient and structural characteristics of soils (Osunde, 1995; Kareem, 2014).

Most tropical soils are highly weathered and leached, some of which are typical Ultisols that are usually characterized by low levels of organic matter and nitrogen content of about $0.3-0.6 \%$ and $0.03-0.05 \%$ respectively (D'Hoore, 1964). In the past, organic matter build-up was achieved under bush fallow system or shifting cultivation or land rotation as a means of fertility maintenance (Greenland and Nye,1959). But owing to rapidly increasing population, these systems are no more practicable due to pressure on land by other sectors of the economy (Yayock et. al., 1988). Under alley cropping with trees that are characterized by profuse litter deposition and nitrogen fixing capacity, soil fertility could be augmented and managed sustainably The use of farmyard manure is limited to small area of land since the demand by large scale farmers or the numerous small scale farmers cannot be met owing to major constraints such as scarcity or insufficient quantities of animal wastes, transportation and labor costs (Yayock et al., 1988).

An alternative and inexpensive technique of improving soil nutrient status is alley cropping where trees help in improving soil fertility (Famuyide and Kareem, 2006). Also, greater erosion resistance, litter deposition, better microclimate and improved rate of mineralization are feasible. In alley cropping farms, effective timing of nutrient release through decision on when to prune the hedge or tree rows for mulching or as green manure is easily determined (Young, 1985; Adebagbo, 1997) in addition to N2 fixation activities. Saginga and Mulongoy (1995) reported that more than $3000 \mathrm{~kg} \mathrm{~N}$ ha-1 yr-1 was realized when Gliricidia and Leucaena hedge rows were pruned and their nitrogen content in the range of $40-70 \mathrm{kgNha}-1$ per season was released to crops. With Albizia lebbeck which is capable of fixing high amount of nitrogen (Dommergues,1987) because most soils in the tropics harbor the Bradyrhizobium strains of nitrogen fixing bacteria needed for nodulation which is present in this species (A. lebbeck) as in other nitrogen fixing tree legumes (Kareem and Animasaun, 2018). 
Thus, the objective of this study is to investigate the influence of Albizia lebbeck on the soil fertility and potato (Solanum tuberosum) yield under alley cropping within five planting seasons.

\section{MATERIALS AND METHOD}

\subsection{The Study Area}

The experiment was carried out in the Teaching and Research Farm of the Department of Agricultural Extension and Management, Federal College of Forestry, Bauchi Road, Jos, Plateau State, Nigeria in the north -eastern part of the Jos city. The Jos Plateau is located in the Northern Guinea Savanna but owing to its distinctive features, it has been mapped out separately from the rest of the Northern Guinea Savanna Zone (Keay, 1959). The Jos Plateau lies between latitude 80 $501 \mathrm{~N}$ and $100101 \mathrm{~N}$ and longitude $80221 \mathrm{E}$ and 90 301E (Udo, 1978). The average elevation is about $1250 \mathrm{~m}$ above sea level while its height above the surrounding plains is about $600 \mathrm{~m}$ and the highest point is about $1777 \mathrm{~m}$ above mean sea level which is about $20 \mathrm{~km}$ eastwards from Shere Hill. Also, a number of relatively low plains are found at the boundaries of the Jos Plateau, at the north-east, it is surrounded by the Bauchi plains, Jama'- Kaduna plains to the north-west and the Benue lowlands to the South. The Jos Plateau is about $8,600 \mathrm{~km} 2$. its north to south length is about $105 \mathrm{~km}$ and $81 \mathrm{~km}$ from east to west and almost occupies the center of the Nigeria's physical space (Keay, 1951; Keay, 1959; Hill, 1978; Davis, 1973; Morgan, 1979; Eziashi, 1995).

\subsection{Pre-Experimental Soil Analysis}

In order to assess the initial nutrient status of the experimental site and use the result of the laboratory analysis as basis for the block design, soil nutrient analysis was carried out. Prior to blocking of the experimental site into three parts to represent the three blocks, three portions or locations were randomly selected (as major locations). This was followed by random selection of four sub-locations from each major location. Subsequently, from each sub-location, soil samples were collected at three depths: 0-10, 10-25, and 25-40 (cm). Composite samples from each major location were used for analysis (that is, the three major locations were assigned Arabic numerals 1, 2, and 3, their corresponding sub-locations were 1a, 1b, 1c, 1d; 2a, 2b, 2c, 2d; 3a, 3b, 3c, 3d). Each sub-location was at 3 soil depths represented in Roman numerals i, ii, and iii. To make composite samples, combinations of ai, + bi + ci, di; aii + bii + cii, dii and aiii + biii + ciii, diii were produced).Thus, a total number of 9 samples ( 3 from each of the major locations) were analyzed and taken as pre-experimental site nutrient status (Tables 1 and 2).

Furthermore, each sample was meticulously put in polythene bags separately, labeled and taken to the laboratory, removed from the polythene bags, air dried, ground, sieved with $2 \mathrm{~mm}$ sieve, smooth and coarse samples weighed separately, the percentage of the coarse portion determined and smooth portion subjected to laboratory analysis. Also, a soil profile was dug at a suitable place in the experiment site. This paved way to have the knowledge of the different horizons in the soil profile, ensured proper identification and classification of the different soil types (for example, Entisols, Inceptisols, Alfisols and Ultisols).It is pertinent to mention here that the same soil sample analytical procedures were employed before (pre) and after (post) the experiment. Determination of the particle size distribution of the soil samples was done by using the hydrometer method (Day, 1965) and separated into sand, silt and clay and expressed in 
percentages, while the $\mathrm{pH} \quad(1: 2: 5)$ in water and $\mathrm{KCl}$ was determined electronically by using a functional $\mathrm{pH}$ meter. The percentage organic carbon content was determined with the aid of potassium dichromate method of Walkey and Black (1974), available phosphorus by Bray and Kurtz (1945) method and total nitrogen by Kjdeldal method (Jackson, 1962). The results obtained are presented in Table 2. Flame photometer was employed in the determination of the exchangeable cations (bases) such as $\mathrm{Na}$ and $\mathrm{K}$ while estimation of the $\mathrm{Ca}, \mathrm{Mg}$ was done by means of atomic absorption spectrometer (AAS). Effective cation exchange capacity (ECEC) was determined by summation method, following the extraction of exchangeable acidity with the aid of IN KCL. Coleman (in Kamprath, 1984) suggested that the determination of CEC through the summation of exchangeable bases plus KCL exchangeable acidity serves as a more realistic method of evaluating the actual amount of bases experienced by plants.

The experimental design employed was randomized complete block design (RCBD) consisting of five (5) treatments and three (3) replicates. A table of random numbers was employed in assigning treatments to each block. The five treatments used are as follows:

To: Potato planted on flat bed without tree rows and green manure of A. lebbeck, T1: Potato planted in the alleys of A. lebbeck without green manure, T2 : Potato planted with green manure of A. lebbeck at 5 ton ha- 1 without its tree rows, T3 : Potato planted in alleys of A. lebbeck tree rows with its green manure at 5 tonha -1 and T4 : Potato planted in alleys of A. lebbeck tree rows with its green manure at 10 ton ha -1

Each plot in a block was $3 \mathrm{~m} \times 2 \mathrm{~m}$, the green manure was single application two weeks before planting the pre - sprouted potato tubers (bertita variety). A. lebbeck tree seedlings had early been raised prior to planting (seedlings were 6 months old before planting with well developed root system $(0.60 \mathrm{~m}$ and $2.0 \mathrm{~m}$ within and between rows respectively). All necessary tending operations were carried out. Analysis of variance (ANOVA) was employed in analyzing the data collected on the soil samples, morphological parameters (plant height, number of leaves, stem count, collar girth) and yield parameters (tuber count and tuber weight) in order to find out if there were significant differences among treatments and blocks owing to the possible influence of the green manure of A. lebbeck and its tree rows. Duncan's Multiple Range Test (DMRT) was used where significant differences were recorded in separating the mean values of the variables so as to help in giving appropriate recommendations (Table 3).

\subsection{Post - Experimental Soil Sample Collection and Analysis}

Immediately after final harvest at the 5th planting season, soil samples were collected for laboratory analysis by employing the same method of analysis earlier described (in preexperimental soil sample analysis). Samples from the five treatments (T0, T1, T2, T3 and T4) were analyzed (three replications per treatment). A comparison between the results from composite samples of pre and post (final) experiment soil nutrient analysis was made using the analysis of variance technique (ANOVA). Thus, improvement or effect on the nutrient status of the soil due to the nitrogen fixing activities of Albizia lebbeck tree rows and incorporated green manure (of this tree species) was evaluated and all the soil samples were analyzed by the same analyst and with the same sets of chemicals (reagents) at the Soil Science Department of Faculty 
of Agriculture, Ahmadu Bello University, Zaria and Institute of Agricultural Research, ABU, Zaria, Nigeria.

\section{RESULTS AND DISCUSSION}

\subsection{Soil physical properties}

Particle size analysis of the three randomly selected locations at the experimental site (prior to planting which served as three replicates) indicated that the soils in the granite area are predominantly sandy clay loam (Table 1 ). The $0-10 \mathrm{~cm}$ depth indicated that the soil had a very high percentage of sand (61\%). The silt and clay contents were $26 \%$ and $13 \%$ respectively. This agrees with Olowolafe (2007) who observed that the soil in the study area is an Alfisol which is characterized by increase in clay content with increase in soil depth. For the $10-25 \mathrm{~cm}$ and $25-$ 40 soil depths, the soil texture is sandy clay loam due to the fact that the sand had the highest percentage. It was observed that the sand and silt proportions decreased with increasing depth (from $0-10,10-25,25-40 \mathrm{~cm}$ depth) while the clay content increased with depth. For instance, the $0-10 \mathrm{~cm}$ depth had $13 \%$ clay which increased to 23 and 33 percent respectively and at $10-25 \mathrm{~cm}$ and at $25-40 \mathrm{~cm}$ depths. This supports the classification as Alfisol owing to increase in clay content with depth which is an important property of Alfisol. However, analysis of variance indicated no significant difference in the $\%$ clay at the three soil depths (Table 1 ).

The nine (9) samples from the three soil depths of T4 were predominantly sandy loam (except two samples) probably because $\mathrm{T} 4$ received the highest rate of green manure application (10 ton ha-1). This must have increased the ratio of smooth to coarse fragment in favor of smooth. T1, T2 $\neg$ and T3 had three (3) of their replicates (samples) being sandy clay loam as opposed to T4 with only two (2). Though T0 also had only two of its nine samples being sandy clay loam which could be attributed to the initial textural class of T0 and probably little fertility gradient as no green manure was applied to the treatment (i.e. T0). There was little (non-significant) difference between the pre and post planting soil texture which was probably the reason why analysis of variance on the clay content indicated no significant difference in the soil texture before and after planting. This agrees with Olowolafe (2003) who had earlier observed that soils developed from granites are mainly loamy textured with sandy clay loam, clay loam and sandy loam constituting the dominant textural classes.

\subsection{Chemical properties of the soil samples (before and after planting)}

The significant difference in block effect with regard to $\mathrm{pH}$ at $10-25 \mathrm{~cm}$ and $25-40 \mathrm{~cm}$ soil depths $(\mathrm{P}<0.01$ and $\mathrm{P}<0.05$ respectively) was observed and this could be attributed to addition of organic matter in form of green manure from Albizia lebbeck. Since the $\mathrm{pH}(\mathrm{H} 20)$ was initially low (4.5) before planting which made the soil very strongly acid (Troug, 1948; Olowolafe, 2003) but rose to a range of 5.1 to 5.4 in T2-T4 which indicated the influence of the green manure application (Table 2). Kunishi (1982) had earlier observed from a study that organic matter raised the soil $\mathrm{pH}$, helped in ameliorating phyto-toxicity in acid soils, decrease soluble manganese and exchangeable aluminium (Al) and increased calcium and available phosphorus. Olowolafe (2003) had also reported that the addition of more organic matter led to the release of more basic cations that resulted in the improvement of base saturation. Soil $\mathrm{pH}$ 
indicated no significant difference at $0-10 \mathrm{~cm}$ depth probably as result of crop/plant absorption or leaching. The soil structure also could have been improved probably owing to the application of the organic manure in T2, T3 and T4 which could have probably improved infiltration and porosity of the soil. Thus, the green manure applied and the tree rows of A. lebbeck might had reduced the acidity of the soil, which brought about better yield of potato in T1-T4 over that of T0. At $0-10 \mathrm{~cm}$ depth, available $\mathrm{P}$ increased to $24.62 \mathrm{pp}$ in $\mathrm{T} 2$ but decreased to a range of 3.7 18.90pp in T0, T1,T3 and T4 and those treatments with fairly low values could be as a result of lower fixation rate and higher rate of absorption by plants (A. lebbeck and potato) in the treatments. 


\begin{tabular}{|c|c|c|c|c|c|c|c|c|c|c|c|c|c|}
\hline \multirow{2}{*}{\multicolumn{2}{|c|}{$\begin{array}{l}\text { Soil Depth } \\
(\mathrm{cm})\end{array}$}} & \multicolumn{4}{|c|}{ Replicate 1} & \multicolumn{4}{|c|}{ Replicate 2} & \multicolumn{4}{|c|}{$\bar{L}$} \\
\hline & & \multirow{2}{*}{ Sand } & \multirow[t]{2}{*}{ Silt } & \multirow[t]{2}{*}{ Clay } & \multirow[t]{2}{*}{ TC } & \multirow[t]{2}{*}{ Sand } & \multirow[t]{2}{*}{ Silt } & \multirow[t]{2}{*}{ Clay } & \multirow[t]{2}{*}{ TC } & \multirow[t]{2}{*}{ Sand } & \multirow[t]{2}{*}{ Silt } & \multirow[t]{2}{*}{ Clay } & \multirow[t]{2}{*}{$\mathrm{TC}$} \\
\hline $\begin{array}{l}\text { Bef } \\
\text { plaa }\end{array}$ & $\begin{array}{l}\text { ore } \\
\text { tting }\end{array}$ & & & & & & & & & & & & \\
\hline & $0-10$ & 61 & 26 & 13 & SL & 47 & 18 & 35 & $\mathrm{SCL}$ & 61 & 22 & 17 & SL \\
\hline & $10-25$ & 59 & 18 & 23 & $\mathrm{SCL}$ & 61 & 14 & 25 & $\mathrm{SCL}$ & 61 & 14 & 25 & $\mathrm{SCL}$ \\
\hline & $25-40$ & 51 & 16 & 33 & SCL & 53 & 16 & 31 & SCL & 49 & 16 & 35 & $\mathrm{SCL}$ \\
\hline \multicolumn{14}{|c|}{ After Planting } \\
\hline $\mathrm{T}_{0}$ & $0-10$ & 75 & 12 & 13 & SL & 65 & 18 & 17 & SL & 67 & 18 & 15 & $\mathrm{SL}$ \\
\hline & $10-25$ & 71 & 14 & 15 & SL & 61 & 18 & 21 & SCL & 63 & 18 & 19 & $S L$ \\
\hline & $25-40$ & 65 & 16 & 19 & SL & 61 & 16 & 23 & SL & 61 & 16 & 23 & $\mathrm{SCL}$ \\
\hline \multirow[t]{3}{*}{$\mathrm{T}_{1}$} & $0-10$ & 75 & 12 & 13 & SL & 67 & 20 & 13 & SL & 63 & 22 & 15 & $\mathrm{SCL}$ \\
\hline & $10-25$ & 71 & 12 & 17 & SL & 65 & 18 & 17 & SL & 49 & 24 & 27 & $\mathrm{SCL}$ \\
\hline & $25-40$ & 69 & 12 & 19 & SL & 61 & 16 & 23 & SCL & 63 & 22 & 15 & $\mathrm{SL}$ \\
\hline \multirow[t]{3}{*}{$\mathrm{T}_{2}$} & $0-10$ & 69 & 16 & 15 & SL & 63 & 16 & 21 & SCL & 61 & 18 & 21 & $\mathrm{SCL}$ \\
\hline & $10-25$ & 69 & 14 & 17 & SL & 67 & 18 & 15 & SL & 59 & 16 & 25 & $\mathrm{SCL}$ \\
\hline & $25-40$ & 63 & 18 & 19 & SL & 71 & 18 & 11 & SL & 63 & 22 & 15 & $\mathrm{SL}$ \\
\hline \multirow[t]{3}{*}{$\mathrm{T}_{3}$} & $0-10$ & 75 & 12 & 13 & SL & 77 & 20 & 03 & SL & 67 & 20 & 13 & SL \\
\hline & $10-25$ & 71 & 12 & 17 & SL & 67 & 20 & 13 & SL & 65 & 16 & 19 & SL \\
\hline & $25-40$ & 59 & 24 & 17 & SL & 61 & 16 & 23 & $\mathrm{SCL}$ & 61 & 16 & 23 & $\mathrm{SCL}$ \\
\hline \multirow[t]{3}{*}{$\mathrm{T}_{4}$} & $0-10$ & 61 & 22 & 17 & SL & 61 & 16 & 23 & SCL & 61 & 22 & 17 & $\mathrm{SL}$ \\
\hline & $10-25$ & 65 & 16 & 19 & SL & 65 & 16 & 19 & SL & 59 & 20 & 21 & $S L$ \\
\hline & $25-40$ & 63 & 14 & 23 & $\mathrm{SCL}$ & 63 & 20 & 17 & SL & 67 & 22 & 11 & SL \\
\hline
\end{tabular}

Magnesium (Mg) is one of the exchangeable cations that dominates the exchange site of the soils (Table 1).The significant effect of blocks on $\mathrm{Mg}$ content at $0-10 \mathrm{~cm}$ depth could be attributed to the influence of fertility gradient (in respect of block) at the experimental site. Generally, soils derived from granites are low or very low in exchangeable Ca and Mg (Olowolafe, 2003). Similarly, the significant effect of the treatments on K levels at $0-10 \mathrm{~cm}$ and $10-25 \mathrm{~cm}$ could be as a result of the application of green manure which might have influenced the $\mathrm{K}$ content in the soil samples from the treatments ((Table 2). The generally low $\mathrm{K}$ levels which could be as result of leaching and the low K content of the soil parent material as earlier reported by Olowolafe and Dung (2000). The non-significant effect of the treatments on Na observed at all soil depths could be attributed to the low level of variations among the mean values of the treatment which ranged from $0.15-0.26 \mathrm{cmol}(+) \mathrm{kg}-1$ which is not enough to bring about significant differences (Table 2).

The observed decrease in the effective cation exchange capacity (ECEC) from a range of 6.12 to 6.62 downwards the soil strata $(0-$ $40 \mathrm{~cm}$ depth) before planting to a range of 3.65 to 5.79 (Table 2) down the strata $(0-40 \mathrm{~cm}$ depth) after planting could be due to absorption by plants, crop removal. Also, the values of the ECEC reduced because of the reduction in the values of exchangeable cations and exchangeable acidity since ECEC is the summation (addition) of the exchangeable cations and exchangeable acidity (Table 2). Therefore, the increase in exchangeable acidity and ECEC from the surface soil to the deeper strata of the soil (subsoil) in the study site could be as a result of infiltration of the exchangeable cations or their absorption by the potato crops for growth and yield. This is in line with the earlier observation made by Olowolafe and Dung (2000) in respect of soils derived from the biotitegranite on the Jos Plateau (Nigeria) with regard to their nutrient status and management for sustainable agriculture. Apart from factors such as infiltration, absorption by crops (crop removal), mini- erosion could also be a contributory factor for the decline in exchangeable acidity and ECEC in the surface soil. This agrees with the reports by Lal (1981) and Olowolafe (2007) who observed that considerable or substantial proportion of topsoil nutrients are lost as a result of erosion.

With regard to the yield, it was obvious from the data collected that T4 had the highest values in growth and yield (tuber count, tuber size, tuber weight) values in all the five cropping seasons owing to the fact that it was the treatment that received the highest level of 
green manure application (10 ton/ha) with tree rows of A. lebbeck.. Also, significant differences were observed at $1 \%$ probability level (Table 3, Plate 1).

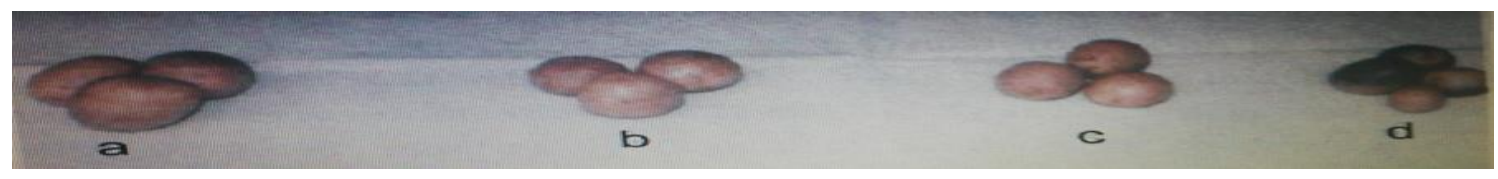

Plate 1: Different sizes of harvested potato tubers (a: $>50 \mathrm{~mm}, \mathrm{~b}: 40-50 \mathrm{~mm}$ c: $30-40 \mathrm{~mm}, \mathrm{~d}:<30 \mathrm{~mm}$ in diameter)

Table 2: Some chemical properties of the pre-experimental soil samples as influenced by the treatments after planting at three soil depths

\begin{tabular}{|c|c|c|c|c|c|c|c|c|c|c|c|}
\hline Treatments & $\frac{\mathrm{pH}}{\mathrm{H}_{2} \mathrm{O} \mathrm{KC}}$ & & $\begin{array}{l}\text { OM } \\
(\%)\end{array}$ & $\begin{array}{l}\text { TN } \\
\text { (\%) }\end{array}$ & $\begin{array}{l}\text { Avail. P } \\
\text { (ppm) }\end{array}$ & $\mathrm{Ca}$ & $\mathrm{Mg}$ & \multicolumn{2}{|c|}{$\begin{array}{c}\mathrm{K} \quad \mathrm{Na} \\
\mathrm{cmol}(+) \mathrm{Kg}^{-1}\end{array}$} & E.A & ECEC \\
\hline \multicolumn{12}{|l|}{ Before Planting } \\
\hline $\begin{array}{c}(0-10 \mathrm{~cm} \\
\text { Depth })\end{array}$ & $4.5 b$ & $4.2 a b$ & $1.94 a$ & $0.10 a b$ & $23.45 a$ & $4.07 a$ & $0.78 b$ & $0.22 \mathrm{a}$ & $0.18 a b$ & $0.87 a$ & $6.12 \mathrm{a}$ \\
\hline \multicolumn{12}{|c|}{ After Planting $(0-10 \mathrm{~cm})$} \\
\hline $\mathrm{T}_{0}$ & $5.2 a$ & $4.5 a$ & $1.22 b$ & $0.06 b$ & $15.52 b$ & $2.06 c$ & $0.61 c$ & $0.17 a b$ & $0.15 b$ & $0.73 a$ & $3.72 b$ \\
\hline $\mathrm{T}_{1}$ & $4.5 b$ & 4.3ab & $1.29 b$ & $0.06 b$ & $16.40 \mathrm{~b}$ & $2.07 c$ & $0.63 c$ & $0.11 a b$ & $0.19 a b$ & $0.54 a$ & $3.54 \mathrm{c}$ \\
\hline $\mathrm{T}_{2}$ & $5.2 \mathrm{a}$ & $4.5 a$ & $1.38 b$ & $0.06 b$ & $24.62 a$ & $3.00 \mathrm{ab}$ & $0.72 b$ & $0.14 a b$ & $0.23 a$ & $0.80 a$ & $4.89 a b$ \\
\hline $\mathrm{T}_{3}$ & $5.1 \mathrm{a}$ & $4.0 \mathrm{~b}$ & $1.45 b$ & $0.08 b$ & $6.45 c$ & $2.67 \mathrm{~b}$ & $0.69 c$ & $0.20 \mathrm{a}$ & $0.19 a b$ & $0.73 a$ & $4.48 a b$ \\
\hline $\mathrm{T}_{4}$ & $4.7 a b$ & $4.1 b$ & $1.69 a$ & $0.33 a$ & $18.90 \mathrm{~b}$ & $3.07 a b$ & $0.93 a$ & $0.17 a b$ & $0.20 \mathrm{a}$ & $0.60 a$ & $4.97 a b$ \\
\hline $\begin{array}{l}\text { Before Planting } \\
(10-25 \mathrm{~cm})\end{array}$ & $4.3 b$ & 3.9 & $1.15 b$ & $0.07 a$ & $3.79 c$ & $3.93 a$ & $0.80 \mathrm{~b}$ & $0.15 a$ & $0.20 \mathrm{a}$ & $1.20 \mathrm{a}$ & $6.28 a$ \\
\hline \multicolumn{12}{|c|}{ After Planting $(10-25 \mathrm{~cm})$} \\
\hline $\mathrm{T}_{0}$ & $4.9 b$ & $4.5 \mathrm{a}$ & $1.03 c$ & $0.05 \mathrm{a}$ & $10.92 b$ & $2.40 \mathrm{~b}$ & $0.46 c$ & $0.14 a$ & $0.17 a b$ & $1.13 a$ & $4.30 \mathrm{~b}$ \\
\hline $\mathrm{T}_{1}$ & $4.8 \mathrm{~b}$ & $4.2 \mathrm{ab}$ & $1.24 b$ & $0.07 a$ & $18.22 \mathrm{a}$ & $3.07 a b$ & $1.16 \mathrm{a}$ & $0.11 a$ & $0.20 \mathrm{a}$ & $0.73 b$ & $5.27 a b$ \\
\hline $\mathrm{T}_{2}$ & $5.1 \mathrm{ab}$ & $4.4 \mathrm{a}$ & $1.26 b$ & $0.08 a$ & 13.79ab & $1.81 \mathrm{c}$ & $0.34 c$ & $0.17 a$ & $0.26 a$ & $1.07 a$ & $3.65 b$ \\
\hline $\mathrm{T}_{3}$ & $5.4 a$ & $4.4 a$ & $1.57 a$ & $0.08 \mathrm{a}$ & $7.29 \mathrm{c}$ & $2.87 \mathrm{~b}$ & $0.81 b$ & $0.19 a$ & $0.20 \mathrm{a}$ & $1.47 a$ & $5.54 a b$ \\
\hline $\mathrm{T}_{4}$ & $5.1 a b$ & $4.5 a$ & $1.38 \mathrm{a}$ & $0.08 \mathrm{a}$ & $10.38 b$ & $3.27 a$ & $0.99 b$ & $0.17 a$ & $0.18 a$ & $1.07 a$ & $5.68 a b$ \\
\hline \multicolumn{12}{|l|}{ Before Planting } \\
\hline$(25-40 \mathrm{~cm})$ & $4.3 b$ & $3.7 \mathrm{a}$ & $0.79 c$ & $0.07 a$ & $3.04 b$ & $3.60 \mathrm{a}$ & $0.52 c$ & $0.18 b$ & $0.27 a$ & $1.87 \mathrm{a}$ & $6.44 a$ \\
\hline \multicolumn{12}{|c|}{ After Planting $(25-40 \mathrm{~cm})$} \\
\hline $\mathrm{T}_{0}$ & $5.1 \mathrm{a}$ & $4.6 \mathrm{a}$ & $0.95 c$ & $0.06 \mathrm{a}$ & $4.46 b$ & $2.87 b$ & $1.19 a$ & $0.16 b$ & $0.18 a b$ & $1.40 \mathrm{ab}$ & $5.80 \mathrm{ab}$ \\
\hline $\mathrm{T}_{1}$ & $5.3 a$ & $4.4 \mathrm{a}$ & $1.05 b$ & $0.07 a$ & $3.90 b$ & $2.73 b$ & $0.66 b$ & $0.14 b$ & $0.21 a b$ & $1.13 b$ & $4.87 \mathrm{~b}$ \\
\hline $\mathrm{T}_{2}$ & $4.8 b$ & $4.4 \mathrm{a}$ & $1.14 \mathrm{a}$ & $0.31 b$ & $4.43 b$ & $2.20 c$ & $0.76 b$ & $0.47 a$ & $0.16 a b$ & $1.33 b$ & $4.92 b$ \\
\hline $\mathrm{T}_{3}$ & $5.4 a$ & $4.4 \mathrm{a}$ & $1.15 a$ & $0.07 a$ & $5.02 a$ & $2.53 b$ & $1.07 a$ & $0.16 b$ & $0.16 a b$ & $1.53 a$ & $5.45 b$ \\
\hline $\mathrm{T}_{4}$ & $4.9 b$ & $4.5 a$ & $1.03 b$ & $0.27 b$ & $6.88 a$ & $1.93 c$ & $0.29 c$ & $0.13 b$ & $0.15 a b$ & $1.13 b$ & $3.63 a b$ \\
\hline
\end{tabular}

$\mathrm{OM}=$ Organic Matter, TN = Total Nitrogen, E.A. = Exchangeable Acidity, ECEC Effective Cation Exchange Capacity. Each value represents mean value from three replicates from a treatment. Mean values with the same letters are not significantly different at 5\% Probability level by DMRT 
ISSN: $2456-8643$

Table 3: Seedling Emergence, Growth and yield parameters of Irish potato in the 1st, 2nd, 3rd, 4th and 5th cropping seasons

\begin{tabular}{|c|c|c|c|c|c|c|c|c|}
\hline \multirow{2}{*}{$\begin{array}{l}\text { Treatments } \\
\text { (5) }\end{array}$} & \multirow{2}{*}{$\begin{array}{l}\text { Emergence } \\
\text { \%S.E. } \\
\text { (7 DAP) }\end{array}$} & \multirow[b]{2}{*}{$\begin{array}{l}\text { \%S.E } \\
(14 \text { DAP) }\end{array}$} & \multicolumn{2}{|c|}{ Growth Parameters } & \multirow[b]{2}{*}{$\begin{array}{l}\text { Stem } \\
\text { Count }\end{array}$} & \multirow[b]{2}{*}{$\begin{array}{l}\text { Collar } \\
\text { Girth(cm) }\end{array}$} & \multicolumn{2}{|c|}{ Yield Parameters } \\
\hline & & & $\begin{array}{l}\text { Plant Ht } \\
(\mathrm{cm})\end{array}$ & $\begin{array}{l}\text { Leaf } \\
\text { Count }\end{array}$ & & & $\begin{array}{l}\text { Tuber } \\
\text { Count }\end{array}$ & $\begin{array}{l}\text { Tuber Yield } \\
\text { (t/ha) }\end{array}$ \\
\hline \multicolumn{9}{|l|}{$1^{\text {st }}$ Season } \\
\hline $\mathrm{T}_{0}$ & $70.0 \mathrm{a}$ & $97.0 \mathrm{a}$ & $44.7 d$ & $24.7 d$ & $3.0 \mathrm{a}$ & $2.2 \mathrm{e}$ & $112.3 \mathrm{c}$ & $5.03 d$ \\
\hline$T_{1}$ & $52.06 \mathrm{~b}$ & $98.0 \mathrm{a}$ & $51.3 \mathrm{c}$ & $27.0 \mathrm{~d}$ & 2.7ab & $2.8 \mathrm{~d}$ & $109.0 \mathrm{c}$ & $5.08 d$ \\
\hline $\mathrm{T}_{2}$ & $41.0 \mathrm{c}$ & $97.0 \mathrm{a}$ & $53.7 \mathrm{c}$ & $41.3 b$ & $2.3 a b$ & $3.07 \mathrm{c}$ & $139.0 b$ & $8.36 b$ \\
\hline $\mathrm{T}_{3}$ & $62.0 \mathrm{ab}$ & $97.7 a$ & $55.7 b$ & $35.7 \mathrm{c}$ & $2.3 a b$ & $3.4 b$ & $113.0 \mathrm{c}$ & $7.98 \mathrm{c}$ \\
\hline $\mathrm{T}_{4}$ & $57.3 b$ & $99.0 \mathrm{a}$ & $66.3 a$ & $56.7 a$ & $2.0 \mathrm{~b}$ & $4.5 \mathrm{a}$ & $160.7 a$ & $9.36 \mathrm{a}$ \\
\hline \multicolumn{9}{|l|}{$2^{\text {nd }}$ Season } \\
\hline $\mathrm{T}_{0}$ & $29.7 \mathrm{~b}$ & $92.7 a b$ & $48.0 \mathrm{e}$ & $30.0 c$ & $2.3 b$ & $2.3 \mathrm{e}$ & $79.7 d$ & $5.19 \mathrm{e}$ \\
\hline $\mathrm{T}_{1}$ & $24.3 \mathrm{c}$ & $90.0 \mathrm{ab}$ & $55.7 d$ & $35.0 \mathrm{c}$ & $2.7 a$ & $3.0 \mathrm{~d}$ & $111.0 \mathrm{c}$ & $5.43 d$ \\
\hline $\mathrm{T}_{2}$ & $24.0 \mathrm{c}$ & $87.0 \mathrm{~b}$ & $58.7 \mathrm{c}$ & $53.0 \mathrm{~b}$ & $3.0 \mathrm{a}$ & $3.4 \mathrm{c}$ & $153.7 a$ & $9.72 b$ \\
\hline$T_{3}$ & $33.7 a$ & $87.7 \mathrm{~b}$ & $62.3 b$ & $52.0 \mathrm{~b}$ & $2.3 b$ & $3.5 b$ & $127.7 b$ & $8.90 \mathrm{c}$ \\
\hline $\mathrm{T}_{4}$ & $24.7 \mathrm{c}$ & $95.0 \mathrm{a}$ & $68.3 a$ & $67.3 a$ & $3.0 \mathrm{a}$ & $4.7 \mathrm{a}$ & $160.7 a$ & $10.41 a$ \\
\hline \multicolumn{9}{|l|}{$3^{\text {rd }}$ Season } \\
\hline $\mathrm{T}_{0}$ & $58.3 b$ & $94.7 \mathrm{~b}$ & $62.0 \mathrm{c}$ & $36.7 d$ & $3.0 \mathrm{a}$ & $2.4 \mathrm{e}$ & $92.3 \mathrm{c}$ & $5.30 \mathrm{e}$ \\
\hline $\mathrm{T}_{1}$ & $54.7 \mathrm{~b}$ & $98.3 a$ & $65.0 \mathrm{bc}$ & $52.3 \mathrm{c}$ & $3.0 \mathrm{a}$ & $3.3 d$ & $94.7 \mathrm{c}$ & $5.40 \mathrm{~d}$ \\
\hline $\mathrm{T}_{2}$ & $43.7 \mathrm{c}$ & $98.0 \mathrm{a}$ & $67.7 b$ & $61.7 \mathrm{~b}$ & $3.0 \mathrm{a}$ & $3.6 \mathrm{c}$ & $151.7 \mathrm{a}$ & $9.13 b$ \\
\hline $\mathrm{T}_{3}$ & $71.7 a$ & $97.7 a b$ & $63.7 \mathrm{c}$ & $64.0 \mathrm{~b}$ & $2.7 a$ & $3.5 b$ & $118.0 \mathrm{~b}$ & $8.61 \mathrm{c}$ \\
\hline $\mathrm{T}_{4}$ & $56.7 \mathrm{~b}$ & $97.0 \mathrm{ab}$ & $75.3 a$ & $70.3 a$ & $2.7 a$ & $4.9 a$ & $93.7 \mathrm{c}$ & $9.80 a$ \\
\hline \multicolumn{9}{|l|}{$4^{\text {th }}$ Season } \\
\hline $\mathrm{T}_{0}$ & $36.3 b$ & 93.0ab & $64.7 d$ & $44.0 \mathrm{e}$ & $3.0 \mathrm{a}$ & $2.5 \mathrm{e}$ & $95.7 \mathrm{bc}$ & $5.22 \mathrm{~d}$ \\
\hline $\mathrm{T}_{1}$ & $31.0 \mathrm{c}$ & $92.0 \mathrm{~b}$ & $70.3 \mathrm{c}$ & $60.0 \mathrm{~d}$ & $3.0 \mathrm{a}$ & $3.5 d$ & $93.7 c$ & $5.74 \mathrm{c}$ \\
\hline $\mathrm{T}_{2}$ & $29.0 \mathrm{c}$ & $95.0 \mathrm{ab}$ & $76.3 b$ & $66.0 \mathrm{c}$ & $2.0 \mathrm{~b}$ & $4.3 b$ & $142.7 a$ & $9.61 a$ \\
\hline $\mathrm{T}_{3}$ & $33.0 \mathrm{bc}$ & $84.0 \mathrm{c}$ & $74.3 b$ & $72.3 b$ & $2.3 b$ & $4.1 \mathrm{c}$ & $103.3 b$ & $8.90 \mathrm{~b}$ \\
\hline $\mathrm{T}_{4}$ & $41.0 \mathrm{a}$ & $97.0 \mathrm{a}$ & $80.7 a$ & $77.7 a$ & $2.3 b$ & $5.3 a$ & $87.0 d$ & $9.73 a$ \\
\hline \multicolumn{9}{|l|}{$5^{\text {th }}$ Season } \\
\hline $\mathrm{T}_{0}$ & $61.0 \mathrm{a}$ & $93.0 \mathrm{a}$ & $63.7 d$ & $46.0 \mathrm{c}$ & $2.7 a$ & $3.1 \mathrm{e}$ & $97.0 \mathrm{c}$ & $5.28 \mathrm{e}$ \\
\hline $\mathrm{T}_{1}$ & $55.3 a$ & $91.7 a$ & $70.7 \mathrm{c}$ & $72.3 b$ & $2.7 a$ & $3.5 d$ & $91.0 \mathrm{c}$ & $5.85 d$ \\
\hline $\mathrm{T}_{2}$ & $59.0 a$ & $92.3 a$ & $77.3 b$ & $71.0 \mathrm{~b}$ & $2.3 a$ & $4.4 b$ & $160.7 a$ & $9.63 b$ \\
\hline $\mathrm{T}_{3}$ & $59.3 a$ & $94.0 \mathrm{a}$ & $71.3 \mathrm{c}$ & $70.3 b$ & $2.7 a$ & $4.2 \mathrm{c}$ & $142.7 b$ & $9.02 \mathrm{c}$ \\
\hline $\mathrm{T}_{4}$ & $63.0 \mathrm{a}$ & $94.0 \mathrm{a}$ & 82.3a & $78.7 a$ & $2.3 b$ & $5.3 \mathrm{a}$ & $161.7 \mathrm{a}$ & $11.96 a$ \\
\hline
\end{tabular}

S.E. = Seedlings' Emergence. Mean values with the same letters were not signifi- cantly different at 5\% level by Duncan's Multiple Range Test (DMRT). See section 2.2 for what To-T4 denote.

\section{CONCLUSION}

Indubitably, reasonable impact of the Albizia lebbeck trees on the soil physical and chemical properties at the experimental site within the five cropping seasons ( 3 yrs) had been observed. This is not unconnected with the green manure application, litter from the A. lebbeck trees and its N2 fixation activities. Also. better positive effects are expected in the long run in terms of the soil physical characteristics (structure, texture, bulk density, porosity, water holding capacity, permeability/hydraulic conductivity) and chemical properties ( $\mathrm{pH}$,organic matter, total nitrogen, available phosphorus, $\mathrm{K}, \mathrm{Ca}, \mathrm{Mg}, \mathrm{S}, \mathrm{Zn}, \mathrm{Mn}, \mathrm{Bo}, \mathrm{Mo}, \mathrm{Cl}$, exchangeable acidity, cation exchange capacity).Thus, a reasonable improvement/modification on the soil fertility in the agroforestry farm will be achieved which will concomitantly lead to increased yield of crops in the alley cropping farm, reduced cost of production and better microclimatic condition 


\section{REFERENCES}

Adebagbo, C. A. (1997). Local Community Participation in Private Farm Forestry and Shelterbelt Scheme for Combating Desert Encroachment. Proceedings of the 25th Annual Conference of the Forestry Association of Nigeria (FAN) In E. A. Oduwaiye, P. C. Obiaga and J. E. Abu (eds.).Ibadan, Oyo State Nigeria 22nd-26thSept.,1997pp.113-114.

Adepetu,J.A.; Obi,O and Aduayi, E.A. (1979).Changes in Soil Fertility Under Continuous Cultivation and Fertilization in South Western Nigeria.Nigeria Journal.of Agric.Sc.I(1)pp.15-20.

Alasiri,K.O.(1997).SoilManagementStrategiesforHorticulturalCropProductioninNigeria.ISSN07 95-4123,OccasionalPaperNo.38NIHORTIbadan,Nigeria.1997pp.1-9.

Alexander,M.(1982).ResearchtoEnhanceNitrogenFixation:MisplacedEmphasis.PrioritiesinBiotec hnologyResearchforInternationalDevelopments.ProceedingsofaWorkshop.Washington,D.C NationalAcademyPress.pp208-299.

Morgan(Ed):OccasionalPublications(NewSeries)No.14.Dept.ofGeography,UniversityofDurham. $45 \mathrm{pp}$.

Davies,H.R.J.(1973).TropicalAfrica:AnAtlasforRuralDevelopment.CardiffUniv.Wales.pp1-11.

Day,P.R.(1965).ParticleFractionalizationandParticleSizeAnalysis.InC.A.Black(Ed).MethodsofSo ilAnalysis.Argon.MonographAmericanSoc.Argon.MadisonWis.pp.545-567.

D’Hoore,J.L.(1964).SoilMapofAfrica.JointProjectIICommunicationsinTechnicalCooperationinA frica,Lagos.pp1-8.

Eziashi,A.C.(1995).AnalysisandClassificationofNaturalRiverChannelsontheJosPlateau.Ph.D.The sis(Unpub).Dept.ofGeographyandPlanning,FacultyofEnvironmentalSciences,Univ.ofJos.Jos,Nig eria.pp.95-125.

Fomba,V.N,(1998).EffectsofGliricidiasepiumLeafMulchingTimeasGreenManureontheGrowthan dYieldofOkra.Unpub.M.Sc.Thesis.Dept.ofForestResourcesManagement,FacultyofAgric.AndFor estry,UniversityofIbadan,Ibadan-Nigeria.Pp16-58.

Gachene, C.K.K. and Kimaru, G. (eds.) Soil fertility and land productivity: A guide for extension workers in the eastern Africa region. RELMA Technical Handbook Series, 30, Nairobi Kenya. Regional Land Mgt.Unit (RELMA). SwedishIDCA (Sida), 146 + xiv pp Bibliography.

Greenland,D.J.andNyeP.H.(1959).IncreaseintheCarbonandNitrogenContentsofTropicalSoilsunde rNaturalFallow:JournalofSoilScience, 10:284-299.

Hill,I.D.(1976)LandResourcesofCentralNigeria.AgriculturalDevelopmentPossibilities.:heJosPlat eauLandResourcesDevelopmentCentre,MinistryofOverseasDevelopment.2A.:1-8. 
Jackson, M. L.(1962).Soil Chemical Analysis .Prentice Hall, NewYork pp.4-8.

Kamprath,E.J.(1984).FertilityManagementofLowActivityclaysoils.In:SMSS1986.TechnicalMon ographNo.14.ProceedingsofaSymposiumonLowActivityClaySoils.LasVegas,1984pp.91-106.

Kareem,I.A.andFamuyide,O.O.(2006).ManagementStrategiesTowardsCurbingEnvironmentalDe gradation:AgroforestryOptionforArableLands.In:TechnologyandAgriculturalDevelopmentinNige ria(S.O.AdepojuandP.B.Okuneyeeds.)20thProceedingsofFarmMgt.Ass.ofNigeria(Faman)Annual ConferenceHeldinFederalCollegeofForestry,ForestryResearchInstituteofNigeira,PMB2019,Jos18 TH-21STSept.,2006pp541-545.

Kamprath,E.J.(1984).FertilityManagementofLowActivityclaysoils.In:SMSS1986.TechnicalMon ographNo.14.ProceedingsofaSymposiumonLowActivityClaySoils.LasVegas, 1984pp.91-106.

Kareem,I.A.andFamuyide,O.O.(2006).ManagementStrategiesTowardsCurbingEnvironmentalDe gradation:AgroforestryOptionforArableLands.In:TechnologyandAgriculturalDevelopmentinNige ria(S.O.AdepojuandP.B.Okuneyeeds.)20thProceedingsofFarmMgt.Ass.ofNigeria(Faman)Annual ConferenceHeldinFederalCollegeofForestry,ForestryResearchInstituteofNigeira,PMB2019,Jos18 TH-21STSept.,2006pp541-545.

.Kareem, I. A. 2014: Comparative analysis of seasonal effects on the growth performance and yield

of potato (Solanum tuberosum Lin.) under agro -forestry system (alley cropping) with the rattle tree (Albizia lebbeck Benth). Journal of Biology, Agriculture and Healthcare. Vol. 4 No 253950(www.iiste.org)International

Keay,R.W.J.(1951).SomeNotesontheEcologicalStatusofSavannaVegetationinNigeria;

ManagementandConservationofVegetationinAfrica.PP.6-11.

Keay,R.W.J.(1953).AnOutlineofNigerianVegetation.Govt.Printer,Nigeriapp.4-8.

Kunishi,H.M.(1982).CombinedEffectsofLime,PhosphateFertilizerandAl+

onPlantYieldfromanAcidSoilofSouthEasternUnitedStates.SoilSci.134:233-238.

Lal,R.(1981).SoilErosionProblemsonAlfisolsinWesternNigeriaIV.EffectsofErosiononExperiment Plots.Geoderma25:215-230.

Morgan,W.T.W.(1979).TheJosPlateau-

ASurveyofEnvironmentandLandUse.Dept.ofGeography,UniversityofDurham,U.K.OccasionalPu bl.(NewSeries).No.14,

Mulongoy,K.andMerckx,R.1993:SoilOrganicMatterDynamicsandSustainabilityofTropicalAgric. Proc.OfInter

SysnposiumOrganizedbyKatholiekeUniversityLeuvenandInternationalInstituteofTropicalAgricul tureLeuren,Belgium,Nov.,1991. 
Olowolafe,E.A.andDungJ.E.(2000).SoilsDerivedfromBiotite-

GranitesintheJosPlateau,Nigeria:TheirStatusandManagementforSustainableAgriculture.ELSEVI ERScience:Resources,ConservationandRecycling29:231-244.

Olowolafe,E.A.(2003)SoilParentMaterialandSoilPropertiesinTwoSeparateCatchmentsAreasonthe JosPlateau,Nigeria.GeographyJournalKluwerAcademicPublishers,Netherlands56:201-212.

Olowolafe,E.A.(2007).DeforestationEffectsinthePropertiesofanAlfisolontheJosPlateauNigeria.Jo urnalofTropicalAgiculture(inPress).

Osunde,A.O.(1995).AssessmentofSomeNitrogenFixingTreesforIntegrationintoAlleyFarmingSyst emintheWestAfricanSavannas. JournalofAgric.Technology.NBTEKaduna.3(2):1-11.

Sanginga,N.andMulongoyK.(1995).IncreasingBiologicalN2FixationandItsContributiontotheNCy cleinAlleyCroppinginAlleyFarmingandDevelopment.ProceedingoftheInter.Conf.OnAlleyFarmin gIbadan,Nigeria.ProducedbytheAlleyFarmingNetworkforTropicalAfrican.InColl. WiththeIITA,IC RAFandILRI,IITA,Ibadan1995.Pp.90-102.

Troug,E.(1948).PresentStatusandFutureSoilTestingAnalysis.Ann.Arbor 2:191.

Udo, R.K.(1978).GeographicalRegionsofNigeria.Ibadan;London:Heinemannpp.1-14.

Walkey,A.andBlackL.F.(1974).AnExaminationoftheDegtjareffMethodforDeterminingSoilOrgani cMatterandaProposedModification oftheChromicAcidTitration.SoilSci.37:29-38.

Yayock,J.Y.,LombinG.andOwonubiJ.J.(1988).CropScienceandProductioninWarmClimates(In.O naziO.C.Gen.ed.)MacmillanIntermediateAgricultureSeries.MacmillanPublishers

Ltd.LondonandBasingstokepp.1-84.

Young,A.(1985).EffectsofTreesonSoils.CommonwealthSeriesCouncil. pp.

28-41. 